\title{
Subcostal M-mode computerised echocardiography An alternative or complementary approach to parasternal echocardiography?
}

\author{
AZARIA JEAN-JACQUES REIN, ISAAC AZANCOT, ALEX VAN CAO N'GUYEN, \\ JEAN-LUC ADDA, GEORGES GEORGIOPOULOS, ANDREE PIEKARSKI, ROBERT SLAMA
}

From the Cardiology Department, Lariboisiere Hospital, Paris; and Cardiofrance Laboratories, Noisy Le Grand, France

SUMmaRY Subcostal $M$-mode echocardiography has been suggested as a method for assessment of left ventricular size and function. Parasternal and subcostal measurements (direct and derived) of left ventricular function were compared in $\mathbf{3 0}$ healthy young subjects. We calculated instantaneous left ventricular diameter and wall thickness every $10 \mathrm{~ms}$ for both the subcostal and parasternal approaches using a computer program for echocardiographic digitisation and compensation. All variables were filtered to calculate instantaneous first derivative (velocity) and logarithmic derivative (normalised velocity). The program provided normal values for computerised variables of left ventricular function from the subcostal approach. It was found that there was no identity and no correlation or a poor one between subcostal and parasternal left ventricular internal diameters and volumes. The parietal wall thickness was significantly greater using the subcostal approach, and the comparative velocities study showed striking variations between the two approaches, especially in diastole, where the peak lateral wall thinning rate was $20 \%$ lower than the posterior thinning rate.

We conclude that for a normal and young population, the subcostal and standard parasternal data cannot be used interchangeably for precise studies of left ventricular function. The subcostal approach, however, provides useful complementary information about lateral wall motion.

M-mode echocardiography from the subcostal approach is today a well accepted method of investigation. ${ }^{1-3}$ There are, however, no published normal values for the classical echocardiographic variables of left ventricular size and function visualised by this technique. Futhermore, to our knowledge, there are no data relating to instantaneous velocity measurements from the subcostal approach; these data are rare also from the standard parasternal approach. ${ }^{4-7}$

This paper describes our method of digitisation and computerisation for the parasternal echocardiographic variables, especially velocity calculations, and presents our normal values for a young and healthy population. The same method is then used for the subcostal approach, and we present for the first time the normal values of the instantaneous velocities for the diameters and thickness changes of the left ventricular structures recorded in this view. Finally, all the data, including the logarithmic first derivatives, are used

Accepted for publication 22 February 1983 for a detailed comparative study of the parasternal and subcostal techniques.

\section{Patients and methods}

Thirty-two consecutive medical students were studied. Careful examination by a cardiologist included a complete medical history, auscultation, and electrocardiography; one subject with auscultatory findings of mitral valve prolapse (confirmed by echocardiography) and a second with a previous history of rheumatic mitral valve disease were excluded from this study. All the remaining 30 subjects were considered to be healthy and submitted to our echocardiographic laboratory. We could not obtain high quality parasternal echocardiographic recordings in three subjects. In 19 out of the 27 remaining subjects, sufficiently high quality recordings were achieved in both parasternal and subcostal techniques (70\%): these 19 subjects (10 men and nine women) formed the study group. Their ages ranged from 20 to 
27 years (mean 22 years).

All the echocardiographic recordings were performed with an "Irex system II" instrument using black and white photographic paper. A complete M-mode echocardiogram was obtained from the parasternal approach following the recommendations of the American Society of Echocardiography. ${ }^{8}$

A subcostal echocardiogram was then recorded according to the criteria for transducer position and angulation. ${ }^{139}$ In both approaches, five consecutive digitisable cycles were recorded, to reduce as much as possible the respiratory effect on left ventricular measurements.

\section{DATA ANALYSIS}

For each $M$-mode echocardiographic recording, five consecutive cardiac cycles were digitised using an HP 9111 A graphic tablet interfaced with a specially programmed HP $9845 \mathrm{~T}$ calculator ${ }^{10} \mathrm{Q}$ waves of a simultaneously recorded electrocardiogram were used to define each cycle (Fig. 1). At every $10 \mathrm{~ms}$, instantaneous values of left ventricular diameter, and septal and posterior wall thickness were computed and stored (Fig. 1). All these variables were filtered using a three point digital method to calculate instantaneous first derivative (velocity) and logarithmic derivative (normalised velocity). The maximal and mean values of each measurement were calculated. The maximal value of each variable was also calculated during the diastolic period. All these computed values were averaged for the five digitised cycles. Calculations were performed for left ventricular diameter, end-diastolic posterior wall thickness, and end-diastolic septal thickness (Fig. 2).

Left ventricular longitudinal axis (L) was derived from the measured equatorial diameter (D) from a hyperbolic relation: $D / L=0.080 \mathrm{D}+0.125$. This rela- tion was obtained in the laboratory from 24 left ventricular angiographies of subjects with and without heart dilatation, digitised frame by frame every $20 \mathrm{~ms}$ to evaluate the corresponding diameter and longitudinal values. ${ }^{1011}$ This relation is very close to that obtained by Teicholz et al. ${ }^{12}$ From longitudinal axis and diameter, left ventricular volumes are calculated $\left(\mathrm{V}=\frac{\pi}{6} \cdot \mathrm{LD}^{2}\right) \cdot$ Myocardial volume $(\mathrm{Vw})$ is calculated from the end-diastolic values of longitudinal axis, equatorial diameter, end-diastolic septal and posterior thickness: $\quad \mathrm{Vw}=\frac{\pi}{6} \quad\left((\mathrm{~L}+\mathrm{H}) \quad(\mathrm{D}+2 \mathrm{H})^{2}-\frac{\pi}{6} \quad \mathrm{LD}^{2}\right)$ where $\mathrm{H}=(\mathrm{Hs}+\mathrm{Hp}) / 2$ assuming an ellipsoidal model with variable wall thickness ( $\mathrm{H}$ in the equatorial plane, $\mathrm{H} / 2$ in the longitudinal plane) as proposed by Rankin et al. ${ }^{13}$ Parietal hypertrophy is quantified using the end-diastolic values of $H p / D$ and of $V w / V$.

\section{STATISTICAL ANALYSIS}

For each variable, the corresponding values, using parasternal and subcostal approaches, were compared.

All paired data were automatically analysed for basic statistics, Student's paired tests, and linear regression analysis.

\section{Results}

High quality subcostal echoes were obtained in 19 subjects $(70 \%)$.

\section{LEFT VENTRICULAR DIMENSIONS (Table 1)}

Comparing left ventricular internal dimensions (D) there was no significant difference between the two techniques for the paired values at end-diastole or at
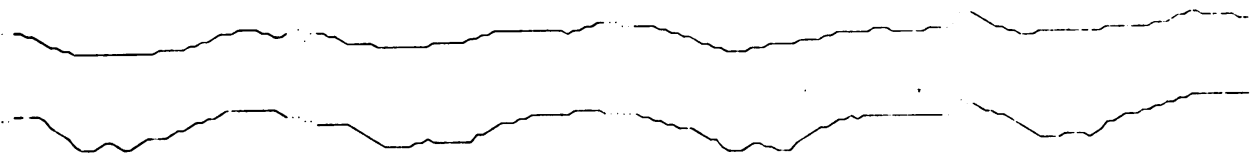

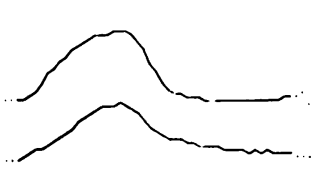

Cycle 2

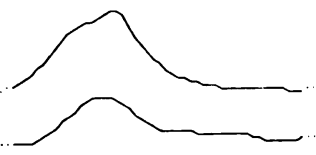

Cycle 3

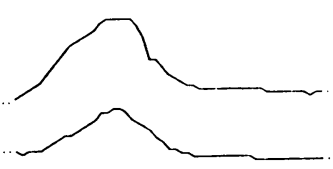

Cycle 4

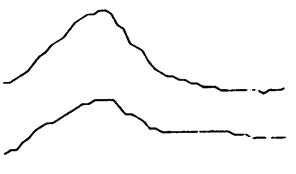

Cycle 5

Fig. 1 Digitised and computer processed M-mode echocardiographic data. 

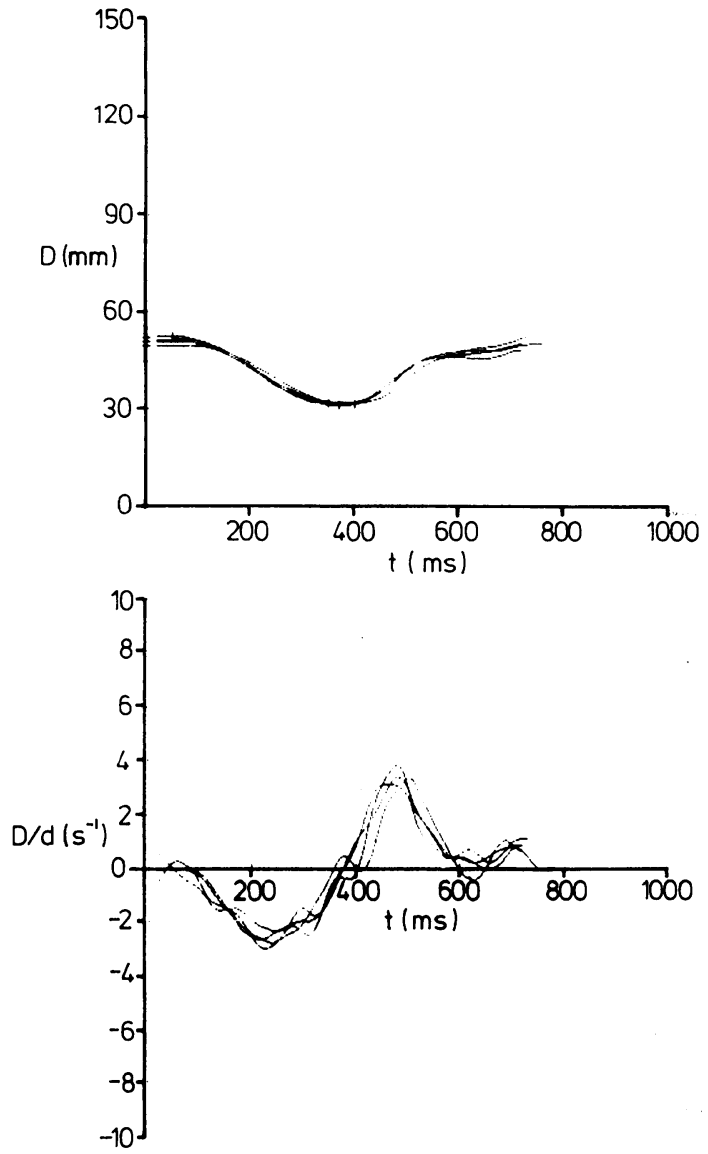

Fig. 2 Graphic representation of calculated variables for left ventricular internal diameter (D) (upper panel) and for its logarithmic first derivative (D/d) (lower panel). Five consecutive cycles are superimposed. end-systole, but the correlations were poor $(y=0.7 x+$ 15 with $r=0.59$ and $y=0.8 x+8$ with $r=0.53$, respectively). Comparing septal and posterior wall thickness at end-diastole, both thickness values were significantly higher using the subcostal approach $(11 \%$ and $14 \%$, respectively; $p<0.05)$. The correlation was better for posterior wall thickness $(r=0.60)$ and improved normalising posterior wall thickness by the end-diastolic value of $\mathrm{D}: \mathrm{Hp} / \mathrm{Dd}(r=0.68)$. As a mathematical consequence, the corresponding values of the shortening and thickening fractions correlated poorly.

VOLUMES AND MASSES (Table 2)

Similar results were found for end-diastolic and endsystolic left ventricular volumes, directly computed from the corresponding $D$ valves. A slight but not significant tendency was noted from the subcostal approach to overestimate volumes and to underestimate ejection fraction, and cardiac and stroke indexes. As expected from values of septal and posterior wall thickness, the values for myocardial volume $(\mathrm{Vw})$ and normalised myocardial volume were significantly higher using subcostal echocardiography $(21 \%$ and $13 \%$, respectively; $p<0.02$ ). Significant correlations were found only for end-diastolic volume (EDV) and Vw/EDV $(y=0.7 x+41$ with $r=0.59$ and $y=0.9 x+0.1$ with $\mathrm{r}=0.64)$.

\section{VELOCITIES}

Peak normalised velocities during the systolic and the diastolic periods were compared for each subject using parasternal and subcostal approaches (Table 3). Peak velocities of left ventricular diameter shortening and wall thickening were not significantly different. Peak velocities during diastole were significantly lower using subcostal examination: $16 \%$ for left ventricular filling rate $(p<0.005),-20 \%$ for posterior wall thinning rate $(p<0.01)$, and $-30 \%$ for septal

Table 1 Left ventricular dimensions

\begin{tabular}{|c|c|c|c|c|}
\hline Variables & $\begin{array}{l}\text { Parasternal } \\
\text { mean } \pm S D\end{array}$ & $\begin{array}{l}\text { Subcostal } \\
\text { mean } \pm S D\end{array}$ & $\begin{array}{l}\text { Mean } \\
\text { variation }\end{array}$ & $\begin{array}{l}\text { Correlation } \\
\text { "r" value }\end{array}$ \\
\hline $\begin{array}{l}\text { End-diastolic diameter (Dd) (mm) } \\
\text { End-systolic diameter (Ds) (mm) } \\
\text { End-diastolic posterior (or lateral) }\end{array}$ & $\begin{array}{l}50.0 \pm 5 \cdot 16 \\
32 \cdot 8 \pm 3 \cdot 9\end{array}$ & $\begin{array}{l}51 \cdot 5 \pm 6 \cdot 4 \\
346 \pm 5 \cdot 8\end{array}$ & $\begin{array}{l}\text { NS } \\
\text { NS }\end{array}$ & $\begin{array}{l}0.59 \\
0.53\end{array}$ \\
\hline $\begin{array}{l}\text { wall thickness (Hp) (mm) } \\
\text { End-diastolic septal }\end{array}$ & $5 \cdot 9 \pm 1 \cdot 4$ & $6.7 \pm 1.8$ & $11 \% \star$ & 0.6 \\
\hline $\begin{array}{l}\text { thickness (Hs) (mm) } \\
\text { Hs/Hp } \\
\text { Hp/Dd } \\
\text { Shortening fraction (\%) } \\
\text { Posterior wall thickening }\end{array}$ & $\begin{array}{l}5 \cdot 2 \pm 1 \cdot 3 \\
0.9 \pm 0.1 \\
0.12 \pm 0.02 \\
34 \cdot 5 \pm 3.7\end{array}$ & $\begin{array}{l}6 \cdot 1 \pm 1 \cdot 2 \\
0.9 \pm 0.1 \\
0.13 \pm 0.04 \\
33 \cdot 1 \pm 5 \cdot 2\end{array}$ & $\begin{array}{l}14 \% \star \\
\text { NS } \\
\text { NS } \\
\text { NS }\end{array}$ & $\begin{array}{l}\text { NS } \\
\text { NS } \\
0.68 \\
\text { NS }\end{array}$ \\
\hline $\begin{array}{l}\text { fraction }(\%) \\
\text { Septal thickening fractions }(\%)\end{array}$ & $\begin{array}{r}161 \pm 50 \\
93 \pm 26\end{array}$ & $\begin{array}{r}142 \pm 64 \\
77 \pm 30\end{array}$ & $\begin{array}{l}\text { NS } \\
\text { NS }\end{array}$ & $\begin{array}{l}0.53 \\
\text { NS }\end{array}$ \\
\hline
\end{tabular}

$\star \mathrm{p}<0.05$.

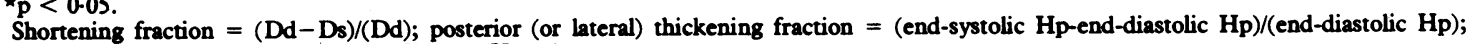
septal thickening fraction $=\left(\mathrm{Hs}_{(e)}-\mathrm{Hs}_{(\mathrm{ed})}\right) /\left(\mathrm{Hs}_{(\mathrm{ed})}\right)$. 
Table 2 Volumes and masses

\begin{tabular}{|c|c|c|c|c|}
\hline Variables & $\begin{array}{l}\text { Parasternal } \\
\text { mean } \pm S D\end{array}$ & $\begin{array}{l}\text { Subcostal } \\
\text { mean } \pm S D\end{array}$ & $\begin{array}{l}\text { Mean } \\
\text { variation }\end{array}$ & $\begin{array}{l}\text { Correlation } \\
\text { "r" valuee }\end{array}$ \\
\hline $\begin{array}{l}\text { End-diastolic volume }(\mathrm{ml}) \\
\text { End-systolic volume }(\mathrm{ml}) \\
\text { Ejection fraction }(\%) \\
\text { Myocardial volume }(\mathrm{ml}) \\
\text { Vw/EDV } \\
\text { Cardiac index }\left(1 / \mathrm{min} \text { per } \mathrm{m}^{2}\right) \\
\text { Stroke index } \mathrm{ml} / \mathrm{m}^{2}\end{array}$ & $\begin{array}{l}126 \pm 30 \\
49 \pm 14 \\
61 \cdot 4 \pm 4 \cdot 8 \\
75 \cdot 7 \pm 27 \\
0.59 \pm 0.12 \\
3 \cdot 5 \pm 0.9 \\
44 \pm 9\end{array}$ & $\begin{array}{l}136 \pm 38 \\
56 \pm 21 \\
59 \cdot 5 \pm 7 \cdot 4 \\
94 \cdot 5 \pm 28 \cdot 5 \\
0.67 \pm 0.18 \\
3 \cdot 3 \pm 0.7 \\
45 \pm 11\end{array}$ & $\begin{array}{l}\text { NS } \\
\text { NS } \\
\text { NS } \\
21 \% \star \star \star \\
13 \% \star \star \\
\text { NS } \\
\text { NS }\end{array}$ & $\begin{array}{l}0.59 \\
\text { NS } \\
\text { NS } \\
\text { NS } \\
0.64 \\
\text { NS } \\
\text { NS }\end{array}$ \\
\hline
\end{tabular}

$\star \star p<0.02$.

$\star \star \star \star \mathrm{p}<0.01$.

$\mathrm{Vw}$, myocardial volume; EDV, end-diastolic volume.

Table 3 Velocity measurements

\begin{tabular}{|c|c|c|c|c|}
\hline Variables & $\begin{array}{l}\text { Parastermal } \\
\text { mean } \pm S D\end{array}$ & $\begin{array}{l}\text { Subcostal } \\
\text { mean } \pm S D\end{array}$ & $\begin{array}{l}\text { Mean } \\
\text { variation }\end{array}$ & $\begin{array}{l}\text { Correlation } \\
\text { "r" valuse }\end{array}$ \\
\hline $\begin{array}{l}\text { V (D) max, systole/s } \\
\text { V (Hp) max, systole/s } \\
\text { V (Hs) max, systole/s } \\
\text { V (D) max, diastole/s } \\
\text { V (Hp) max, diastole/s } \\
\text { V (Hs) max, diastole/s }\end{array}$ & $\begin{array}{l}2 \cdot 3 \pm 0.3 \\
5 \cdot 7 \pm 1 \cdot 5 \\
5 \cdot 5 \pm 1 \\
3 \cdot 56 \pm 0.83 \\
9.37 \pm 2 \cdot 58 \\
6 \cdot 64 \pm 2.58\end{array}$ & $\begin{array}{l}2.2 \pm 0.3 \\
5.2 \pm 1.9 \\
4.9 \pm 1 \cdot 5 \\
3.08 \pm 0.71 \\
7.78 \pm 2.31 \\
5 \cdot 12 \pm 1.87\end{array}$ & $\begin{array}{l}\text { NS } \\
\text { NS } \\
\text { NS } \\
-16 \% \star \star \star \star \\
-20 \% \star \star \star \\
-30 \% \star \star \star \star\end{array}$ & $\begin{array}{l}\text { NS } \\
0.72 \\
\text { NS } \\
0.65 \\
\text { NS } \\
\text { NS }\end{array}$ \\
\hline
\end{tabular}

$\star \star \star \mathrm{p}<0.01$.

$\star \star \star \star \star \mathrm{p}<0-005$

Abbreviations as in Tables 1 and 2.

thinning rate $(p<0.005)$. Significant correlations were only found for peak posterior wall thickening rate $(y=0.9 x+0.1, r=0.72)$ and for peak left ventricular filling rate $(r=0.65)$.

\section{Discussion}

We obtained high quality subcostal echocardiograms in $70 \%$ of a normal healthy population. Starling et $a l .,{ }^{3}$ in their study, included older patients (mean 50 years) and with different cardiac diseases. In spite of that, they were able to make measurements of left ventricular dimension in $63 \%$ of their subcostal echocardiographic recordings. Thus, it seems that the feasibility of subcostal echocardiography does not depend upon the age of the subject or on the presence of cardiac disease, but its success rate is lower than in the standard parasternal echocardiography. In $7 \%$ of the patients in the study of Starling et al. ${ }^{3}$ however, only the subcostal view was available. This may be explained by the fact that their population was older, probably with a higher frequency of hyperinflation and lung disease which impedes a parasternal approach. We obtained good parasternal echocardiograms in all 19 subjects.

To obtain an ideal method of comparison between the two approaches, the ultrasonic beam should be directed, in the subcostal approach as in the parasternal one, in such a way as to intersect the longitudinal axis perpendicularly at the level of the chordae tendineae. In our experience, however, based on cross- sectional echocardiography, this is especially difficult in the subcostal view, because the recorded diameter frequently defines an angle with the true left ventricular internal diameter: the wider the angle, the greater the overestimation. This may explain the slightly higher values of left ventricular internal diameters found in the subcostal technique compared with the parasternal view, even if no statistical significance could be shown. The low value, however, may be the result of the homogeneity of the study population and the narrow range of values. For the same reasons, the cavitary end-diastolic and endsystolic volumes (directly calculated from the diameters) were slightly but not significantly higher in the subcostal group than in the parasternal one, and again did not correlate well. Similarly, the shortening fraction, the ejection fraction, and the cardiac index were slightly but not significantly lower in the subcostal group than in the parasternal one, and again did not correlate well.

Starling et al. ${ }^{3}$ compared the left ventricular echocardiographic volumes with those measured from angiography and found good correlation between them; no data are available, however, from this study about the direct comparison between the two echocardiographic techniques with respect to the left ventricular volumes. In spite of that, they concluded that the subxiphoid echocardiographic technique was comparable to the standard left parasternal approach for estimating left ventricular size. Our volume data did not show a good correlation between the two 
techniques. Starling et al. included four patients with a large left ventricle (end-diastolic diameter $55 \mathrm{~mm}$ ) and this may explain in part their correlation, since the more dilated the left ventricle, the more spheric the cavity, with a narrower angle between the true and recorded left ventricular short axis diameter. These patients also influence the regression curve.

The angulation problems might not be the sole factor in the overestimation of the left ventricle from the subcostal view since anatomical differences may exist between the structures visualised in the parasternal and subcostal examinations, and are particularly critical for the comparison between parasternal and subcostal wall thickness values. From the study of Greenbaum et al., ${ }^{14}$ dealing with myocardial architecture of the different left ventricular regions, it appears that the lateral wall thickness (measured after dissection) was $14 \%$ higher than the posterior wall. These findings would be consistent with our results: using the subcostal approach we found an overestimation of septal and posterior wall thickness and myocardial volume of $14 \%, 11 \%$, and $21 \%$, respectively. The angulation problems already discussed may also have a significant influence in the discrepancy between the corresponding thickness values using both approaches. When posterior wall thickness was normalised for the end-diastolic $D$ value, difference was no longer significant and there was a fair correlation between these parasternal and subcostal variables $(r=0.68)$. The influence of this normalisation was probably to minimise the overestimation and the variability caused by the angulation problem, since we augmented the numerator (septal wall thickness) as well as the denominator (end-diastolic diameter) by the same factor of error. The same reasoning can be applied to the normalisation of myocardial volume by end-diastolic volume.

Few data have been published about the study of instantaneous left ventricular velocities; we should mention, however, that our ranges of posterior wall thinning and thickening velocities and peak left ventricular filling rate (in the classical parasternal approach) overlap the ranges of those same variables given by Traill et al. ${ }^{6}$ (Table 4). It is interesting that left ventricular internal diameter velocity changes showed a tendency to underestimation when the subcostal approach was used. With respect to velocity measurements, the most striking and significant mean

Table 4 Instantaneous velocities in our study and that of Traill et al. 6

\begin{tabular}{lcc}
\hline Variables & Rein et al & Traill et al \\
\hline V (D) max, diastole/s & $144 \pm 39$ & $160 \pm 30$ \\
V (Hp) max, systole/s & $48 \pm 12$ & $46 \pm 12$ \\
V (Hp) max, diastole/s & $94 \pm 31$ & $107 \pm 17$ \\
\hline
\end{tabular}

Abbreviations as in previous tables. variations between the two methods appeared for the diastolic peak rates of septal and posterior wall thinning. Thus, it seems that the peak rate of lateral wall thinning is $20 \%$ lower than the peak rate of posterior wall thinning. The maximum velocity for the lower septum is also $30 \%$ lower than for the upper septum.

In summary, the lack of correlation between the parasternal and subcostal echo methods in our population implies that the subcostal approach cannot be used interchangeably with the standard parasternal echocardiography. The given subcostal normal values for classical left ventricular size and function as well as the computer derived measurements for instantaneous cavity and wall velocity will, however, probably prove very useful for an accurate analysis of lateral left ventricular wall motion, which is not readily available from the parasternal view. The subcostal approach is thus not an alternative but a complementary method of investigation to standard M-mode parasternal echocardiography; the additional information may be of particular importance in patients with coronary artery disease and left ventricular asynergy.

\section{References}

1 Chang S, Feigenbaum H, Dillon J. Subxiphoid echocardiography. Chest 1975; 68: 233-5.

2 Kline LE, Crawford MH, Macdonald WJ Jr, Schelbert H, O'Rourke RA, Moser KM. Noninvasive assessment of left ventricular performance in patients with chronic obstructive pulmonary disease. Chest $1977 ; 72$ : 558-64.

3 Starling MR, Crawford MH, O'Rourke RA, Groves BM, Amon KW. Accuracy of subxiphoid echocardiography for assessing left ventricular size and performance. Circulation 1980; 61: 367-73.

4 Gibson DG, Brown D. Measurement of instantaneous left ventricular dimension and filling rate in man, using echocardiography. Br Heart f 1973; 35: 1141-9.

5 Gibson DG, Greenbaum R, Marier DL, Brown DJ. Clinical significance of early diasto!ic changes in left ventricular wall thickness. Eur Heart $\mathcal{F}$ 1980; 1 (suppl A): 157-63.

6 Traill TA, Gibson DG, Brown DJ. Study of left ventricular wall thickness and dimension changes using echocardiography. Br Heart f 1978; 40: 162-9.

7 Shapiro E, Marier DL, St John Sutton MG, Gibson DG. Regional non-uniformity of wall dynamics in normal left ventricle. Br Heart $f$ 1981; 45: 264-70.

8 Sahn DJ, De Maria AN, Kisslo J, Weyman A. Recommendations regarding quantitation in $\mathrm{M}$-mode echocardiography: results of a survey of echocardiography measurements. Circulation 1978; 58: 1072-83.

9 Feigenbaum H. Echocardiography. Philadelphia: Lea \& Febiger, 1981: 54-5, 127-9.

10 Azancot I, Piekarski A, N'Guyen A, Georgiopoulos G, Babalis D, Slama R. Computerized evaluation of muscle stiffness and muscle contractility using dynamic M-mode studies of left ventricular echograms. In: Computers in cardiology. New York: IEEE Computer Society Press, 1980:463-6. 
11 Azancot I, Slama R, Bouvrain Y. Evaluation de la cinétique de la contraction ventriculaire gauche globale et régionale: etude angiographique image par image sur mini-ordinateur. F Physiol (Paris) 1980; 76: 731-9.

12 Teicholz LE, Kreulen T, Herman MV, Gorlin R. Problems in echocardiographic volume determinations: echocardiographic-angiographic correlations in the presence or absence of asynergy. Am $\mathcal{F}$ Cardiol 1976; 37: 7-11.

13 Rankin JS, McHale PA, Arentzen CE, Ling D, Greenfield JC Jr, Anderson RW. The three dimensional dynamic geometry of the left ventricle in the conscious dog. Circ Res 1976; 39: 304-13.

14 Greenbaum RA, Ho SY, Gibson DG, Becker AE, Anderson RH. Left ventricular fibre architecture in man. Br Heart f 1981; 45: 248-63.

Requests for reprints to Dr A J J Rein, Cardiology Department, Hadassah Hospital, Ein Kerem, Jerusalem, Israel. 